\title{
Limited Tumor Tissue Drug Penetration Contributes to Primary Resistance against Angiogenesis Inhibitors
}

\author{
Szilvia Torok $1,2,3,4$, Melinda Rezeli3, Olga Kelemen ${ }^{1,3}$, Akos Vegvari ${ }^{3,5}$, Kenichi Watanabe3, Yutaka \\ Sugihara ${ }^{3,6}$, Anna Tisza ${ }^{1}$, Timea Marton ${ }^{1}$, Ildiko Kovacs ${ }^{1}$, Jozsef Tovari ${ }^{7}$, Viktoria Laszlo 2,8 , Thomas H. \\ Helbich8, Balazs Hegedus',9,10, Thomas Klikovits², Mir Alireza Hoda², Walter Klepetko², Sandor Paku10,11, \\ Gyorgy Marko-Varga ${ }^{3,12}$, Balazs Dome ${ }^{1,2,4,8} \bowtie$ \\ 1. National Korányi Institute of Pulmonology, Budapest, Hungary; \\ 2. Division of Thoracic Surgery, Department of Surgery, Comprehensive Cancer Center, Medical University of Vienna, Austria; \\ 3. Clinical Protein Science\&Imaging, Biomedical Center, Dept. of Biomedical Engineering, Lund University, Sweden; \\ 4. Department of Thoracic Surgery, Semmelweis University and National Institute of Oncology, Budapest, Hungary; \\ 5. Department of Pharmacology and Toxicology, University of Texas Medical Branch, Galveston, TX, USA; \\ 6. Division of Oncology and Pathology, Department of Clinical Sciences, Lund University, Sweden; \\ 7. Department of Experimental Pharmacology, National Institute of Oncology, Budapest, Hungary; \\ 8. Department of Biomedical Imaging and Image-guided Therapy, Division of Molecular and Gender Imaging, Medical University of Vienna, Vienna, Austria; \\ 9. Department of Thoracic Surgery, Ruhrlandklinik, University Clinic Essen, Germany; \\ 10. Hungarian Academy of Sciences-Semmelweis University, Tumor Progression Research Group, Budapest, Hungary; \\ 11. 1st Institute of Pathology and Experimental Cancer Research, Semmelweis University, Budapest, Hungary; \\ 12. Center of Excellence in Biological and Medical Mass Spectrometry, Lund University, Sweden \\ GMV and BD contributed equally as senior authors to this study.
}

$\triangle$ Corresponding authors: Balazs Dome, MD, PhD; Division of Thoracic Surgery, Comprehensive Cancer Center, Medical University of Vienna; Waehringer Guertel 18-20, A-1090 Vienna, Austria; Phone:+4314040073742; Email: balazs.dome@meduniwien.ac.at. Gyorgy Marko-Varga, PhD; Clinical Protein Science \& Imaging, Biomedical Center, Dept. of Biomedical Engineering, Lund University, BMC D13, SE-221 84 Lund, Sweden; Phone: +46-46-222-3402; Email: Gyorgy.Marko-Varga@bme.lth.se

(C) Ivyspring International Publisher. This is an open access article distributed under the terms of the Creative Commons Attribution (CC BY-NC) license (https://creativecommons.org/licenses/by-nc/4.0/). See http://ivyspring.com/terms for full terms and conditions.

Received: 2016.07.07; Accepted: 2016.11.07; Published: 2017.01.01

\begin{abstract}
Resistance mechanisms against antiangiogenic drugs are unclear. Here, we correlated the antitumor and antivascular properties of five different antiangiogenic receptor tyrosine kinase inhibitors (RTKIs) (motesanib, pazopanib, sorafenib, sunitinib, vatalanib) with their intratumoral distribution data obtained by matrix-assisted laser desorption ionization mass spectrometry imaging (MALDI-MSI). In the first mouse model, only sunitinib exhibited broad-spectrum antivascular and antitumor activities by simultaneously suppressing vascular endothelial growth factor receptor-2 (VEGFR2) and desmin expression, and by increasing intratumoral hypoxia and inhibiting both tumor growth and vascularisation significantly. Importantly, the highest and most homogeneous intratumoral drug concentrations have been found in sunitinib-treated animals. In another animal model, where - in contrast to the first model - vatalanib was detectable at homogeneously high intratumoral concentrations, the drug significantly reduced tumor growth and angiogenesis. In conclusion, the tumor tissue penetration and thus the antiangiogenic and antitumor potential of antiangiogenic RTKIs vary among the tumor models and our study demonstrates the potential of MALDI-MSI to predict the efficacy of unlabelled small molecule antiangiogenic drugs in malignant tissue. Our approach is thus a major technical and preclinical advance demonstrating that primary resistance to angiogenesis inhibitors involves limited tumor tissue drug penetration. We also conclude that MALDI-MSI may significantly contribute to the improvement of antivascular cancer therapies.
\end{abstract}

Key words: matrix assisted laser desorption ionization, imaging mass spectrometry, angiogenesis, receptor tyrosine kinase inhibitor, resistance, cancer 


\section{Introduction}

Since an adequate blood supply is regarded as essential for tumor growth [1], there had been overwhelming optimism that targeting angiogenic pathways would represent an effective treatment strategy in solid tumors. Receptor tyrosine kinase inhibitors (RTKIs) represent a major class of drugs that have been developed to block tumor-induced angiogenesis. In the current study, we investigated the in vivo antitumor and antivascular activities and the tumor tissue drug distribution data of five different RTKIs (motesanib, pazopanib, sorafenib, sunitinib, vatalanib). Out of these five compounds, pazopanib, sorafenib and sunitinib have already been approved by the FDA for advanced renal cancer [2-4]. Additionally, pazopanib is effective in advanced soft tissue sarcoma [2] and sorafenib is available for the treatment of unresectable liver cancer and locally recurrent or metastatic, progressive differentiated thyroid carcinoma refractory to radioactive iodine treatment [3]. Furthermore, sunitinib is approved in progressive well-differentiated pancreatic neuroendocrine tumors and gastrointestinal stromal tumors after disease progression, or intolerance to imatinib mesylate [4]. The two not yet approved drugs, motesanib and vatalanib, are currently investigated in clinical trials. The only study completed so far with motesanib in first- or second line-treated colon cancer patients presents modest efficacy [5], while vatalanib is showing promising results in colon cancer patients only with increased vessel density or low lactate dehydrogenase levels [6-8]. Altogether, although initial results with antiangiogenic RTKIs looked promising and some of them were approved in the early 2000s, subsequent preclinical and clinical studies provided disappointing survival data [9-12]. The limited efficacy of antiangiogenic agents has prompted research into the possible causes behind the resistance against antiangiogenics with the expectation of developing novel and more successful therapeutic approaches. The previously described resistance mechanisms include the development of a more malignant phenotype associated with therapy-induced hypoxia, VEGF-independent endothelial growth driven by various pro-angiogenic cytokines, the mobilization of bone marrow-derived proangiogenic hematopoietic cells or endothelial progenitors and increased tumor invasiveness due to vessel cooption [9-13]. However, the lack of greater clinical success is, at least in part, also due to our limited knowledge on the pharmacokinetic profile, bioavailability and distribution of these drugs at the tumor site as the so far published studies have focused mainly on the measurements of compounds from the blood, urine and occasionally from tissue homogenates [14].

Herein, we utilize mouse models of cancer and matrix-assisted laser desorption ionization mass spectrometry imaging (MALDI-MSI) to study the intratumoral levels and distribution of antiangiogenic RTKIs. We also investigate tumor growth and vascularization, intratumoral hypoxia, tumor capillary wall integrity and the tumor and vascular cell expressions of the target receptors of antiangiogenic RTKIs.

\section{Materials and Methods}

\section{Drugs}

For the in vivo treatments, we selected five different antiangiogenic RTKIs potently inhibiting not only the main angiogenic receptor, vascular endothelial factor receptor-2 (VEGFR2), but also platelet-derived growth factor (PDGF) and fibroblast growth factor (FGF) receptors [15-19]. All drugs were purchased from the LC Laboratories (Woburn, MA, USA; CAS numbers: motesanib: 453562-69-1, pazopanib: 444731-52-6, sorafenib: 284461-73-0, sunitinib: 557795-19-4, vatalanib: $212141-54-3$ ) at $>99 \%$ purity and were suspended in $2 \%$ carboxymethylcellulose with $2 \mathrm{mg} / \mathrm{mL}$ methyl-4-hydroxibenzoate (both from Sigma Aldrich) before treatments. The administration and treatment dose for each compound were established to be tolerable and effective according to the literature [15, 20-35]. Control mice received only the suspending medium.

\section{In vivo tumor models and treatments}

The C26 mouse colon adenocarcinoma cell line was cultured in RPMI 1640 medium supplemented with $10 \%$ fetal bovine serum and $1 \%$ penicillin/streptomycin (all from Sigma Aldrich, Steinheim, Germany) in a humidified atmosphere at $37^{\circ} \mathrm{C}$ and $5 \% \mathrm{CO}_{2}$. Groups of six 8-week-old female Balb/C mice from our colony were inoculated subcutaneously (s.c.) with $2 \times 10^{6}$ C26 cells, as described recently [36]. All RTKI treatments began 2 weeks after tumor cell injection and were performed once daily at a dose of $100 \mathrm{mg} / \mathrm{kg}$ p.o. with a feeding tube 5 times a week for two weeks.

The C38 mouse colorectal carcinoma was maintained by serial s.c. transplantations in 8-week-old female C57Bl/6 mice, as previously described [37, 38]. Tumor tissue was cut into cubes measuring $5 \times 5 \times 5 \mathrm{~mm}$. Animals were anesthetized and one piece of tumor tissue was transplanted into the back of each mouse. Treatments began 13 days after tumor implantation and were performed similarly to that of the C26 model. 
Tumor size was measured three times a week with a caliper and expressed in $\mathrm{mm}^{3}$ by the formula for the volume of a prolate ellipsoid (length $\mathrm{x}$ width2 $\Pi / 6)$ in case of both in vivo models, as described previously [39].

To assess intratumoral hypoxia, a bolus of i.p. pimonidazole $(60 \mathrm{mg} / \mathrm{kg}$; Hypoxyprobe Inc., MA, USA) was administered 2 hours before the mice were sacrificed in both animal models. Two hours after the last RTKI treatment, blood was drawn from the canthus and the animals were sacrificed. Tumors were removed and snap frozen, as described previously [4]. All animal experiments were carried out in accordance with the ARRIVE guidelines [40] and with the animal welfare regulations of the host institutes (permission number: 22.1/722/3/2010).

\section{Compound characterization}

Drugs were dissolved in 50\% methanol (Sigma-Aldrich, Steinheim, Germany) at HPLC grade $(99.8+\%)$ at $0.5 \mathrm{mg} / \mathrm{mL}$ concentration. The matrix $(7.5$ $\mathrm{mg} / \mathrm{mL}$ a-cyano-4-hydroxycinnamic acid, Sigma Aldrich, Steinheim, Germany) was dissolved in 50\% acetonitrile at hypergrade for liquid chromatographymass spectrometry (LC-MS, Merck, Darmstadt, Germany) and $0.1 \%$ trifluoroacetic acid (Sigma-Aldrich, Steinheim, Germany). $1 \mu \mathrm{L}$ of the compound solution was applied with $1 \mu \mathrm{L}$ matrix solution to the MALDI plate. Full mass spectra were obtained by using a MALDI LTQ Orbitrap XL mass spectrometer (Thermo Fisher Scientific, Bremen, Germany) at 60,000 resolution in positive polarity mode. The spots were sampled in survey mode collecting 20 experiments for a single run. The nitrogen laser was set to $10 \mu \mathrm{J}$. The detected precursor ion was fragmentized by using $40 \%$ normalized collision energy (NCE) during a $30 \mathrm{~ms}$ activation time, while activation $\mathrm{Q}$ of 0.250 was applied. The precursor ions were isolated with $\mathrm{m} / \mathrm{z} 2.0$ width and MS/MS spectra were collected at normal scan rate in centroid mode.

\section{Tissue imaging of antiangiogenic RTKIs}

$10-\mu \mathrm{m}$ frozen sections were cut using a cryotome and placed onto glass slides. After drying of the tissue, $0.5 \mathrm{~mL}$ matrix solution was applied stepwise to avoid wetting of the sections by using an airbrush, while its position was kept constant. Full mass spectra were collected by using the Orbitrap mass analyzer at 60,000 resolution (at $\mathrm{m} / \mathrm{z} 400$ ) in positive mode with a 150-800 Da mass range with activated automatic gain control mode. Tissue sections were sampled with 100 $\mu \mathrm{m}$ raster size. The nitrogen laser was operated at 10.0 $\mu \mathrm{J}$. For obtaining MS/MS data, the observed peaks of the parent antiangiogenic drugs were isolated with $\mathrm{m} / \mathrm{z} 2.0$ width isolation window and fragmentized, using $40 \% \mathrm{NCE}, 30 \mathrm{~ms}$ activation time and 0.250 activation $Q$. For MS/MS spectra generation, the minimal signal required was 500 counts, the fragment ions were analyzed in the linear ion trap at normal scan rate. Evaluation of the spectra was performed with Xcalibur v 2.0.7. software, while the visualization of the drug and fragment ion distribution was implemented with the ImageQuest ${ }^{\mathrm{TM}}$ software (both from Thermo Fisher Scientific, San José, CA).

\section{Quantification of the precursor compounds}

For tissue quantification of intratumoral drug concentration, calibration curves of each compound were established on tissue sections of untreated control C26 and C38 tumors. After determining the detection limit of the instrument, drugs were dissolved and diluted in 50\% methanol (concentration range: $0.001-0.5 \mu \mathrm{mol} \mathrm{mL}-1$ ) and $0.5 \mu \mathrm{L}$ from each concentration was applied on the tissue section. Spraying and detection conditions were the same as those during the tissue section analysis of in vivo treated tumors. Average signal intensities of the applied concentrations were measured and normalized to Total Ion Current (TIC) by using Xcalibur v 2.0.7. and ImageQuest ${ }^{\mathrm{TM}}$ softwares. Calibration curves were created (Figure S1) and then used to estimate the tissue drug concentrations of in vivo-treated tumor sections.

\section{Compound detection in the blood}

$20 \mu \mathrm{L}$ of plasma sample was analyzed. Plasma proteins were removed by acetonitrile precipitation. Pierce C18 Tips (Thermo Fisher Scientific, Rockford, IL, USA) were used to concentrate the RTKIs from the precipitated plasma samples following the manufacturer's instructions. $1 \mu \mathrm{L}$ of the sample was applied on the MALDI plate with $1 \mu \mathrm{L}$ matrix solution using the same instrument settings as those for the compound characterization.

Throughout our MS experiments drugs were considered to be identified if the precursor molecule and at least one fragment ion were discovered in the spectra.

\section{Analysis of vascular parameters and target receptors}

For the analysis of RTKI distributions, vascular parameters and target receptor expressions, 10 serial frozen sections were cut from each tumor (Figure S2). Sections \#5 and \#7 were used to analyze the distribution of the given RTKI by MALDI-MSI and for subsequent haematoxylin\&eosin (HE) staining. Sections \#1-4 were labeled with either of the following primary antibodies: anti-FGFR1, anti-PDGFRa, anti-PDGFR $\beta$ and anti-VEGFR2. For hypoxia 
detection (section \#6), we used the Hypoxyprobe-1 Plus Kit. Sections \#8-10 were labeled with either of the following primary antibodies: anti-laminin (for endothelial basement membrane labeling), anti-desmin and anti-a-smooth muscle actin (anti-aSMA) (both for pericyte labeling). All of the above primary antibodies were developed with an appropriate fluorescent secondary antibody. Primary and secondary antibodies and reagents used for immunofluorescence are listed in Table S1.

For intratumoral microvessel area measurements, sections \#1-4, \#6 and \#8-10 were co-stained with anti-mouse CD31 antibody, followed by a counterstain with Hoechst 33342 before mounting under glass coverslips in ProlongGold Antifade Reagent $(20 \mu \mathrm{L}$, Invitrogen, Carlsbad, CA, USA; Catalog number: P36930). Slides were scanned by TissueFAXS (TissueGnostics $\mathrm{GmbH}$, Vienna, Austria) and analyzed by ImageJ and TissueGnostics 4.0.0140 (TissueGnostics $\mathrm{GmbH}$, Vienna, Austria) softwares. Images of ten different necrosis-free intratumoral regions were assessed separately for each section. Microvessel areas were then calculated by counting the number of CD31-positive pixels in the total area of ten intratumoral regions. The percentages of microvessels that were positive for laminin, desmin or aSMA were also calculated. For quantification of VEGFR2 expression, the average numbers of VEGFR2 positive endothelial or tumor cells were calculated. For quantification of hypoxia and PDGFRa, PDGFR $\beta$ and FGFR1 expressions, the percentages of hypoxic regions and positively labeled cells were determined across the entire area of section.

\section{Statistical analysis}

Differences in parametric and non-parametric variables between multiple groups were analyzed using ANOVA and Dunnett's posthoc test or using the Kruskal-Wallis test followed by a posthoc Dunn's multiple comparison test, respectively. For comparing two groups, t- or Mann-Whitney U tests were applied. Differences were considered statistically significant when $\mathrm{P}<0.05$. All Statistical analyses were carried out using GraphPad Prism 5.0 software (GraphPad Inc., San Diego, CA, USA).

Figure 1 shows the flowchart of the experiments.

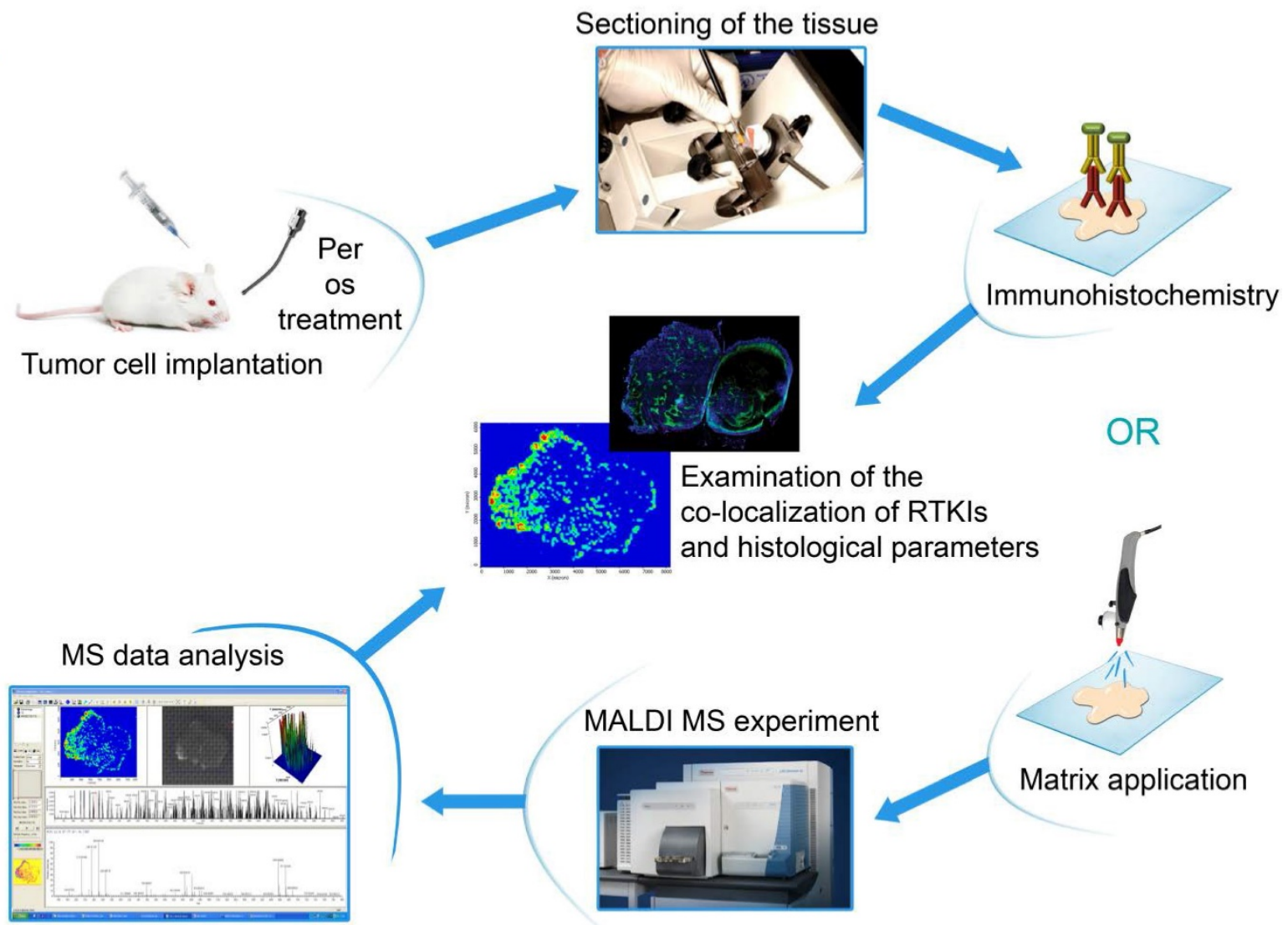

Figure 1. Graphical abstract of the study procedure. Ten serial frozen sections were cut from C26 and C38 mouse tumors treated with five different antiangiogenic RTKIs. Sections were used then to analyze drug dispersal by MALDI-MSI and, moreover, for HE staining and immunolabeling with antibodies against CD31, laminin, desmin, $\alpha$ SMA and the target receptors of RTKIs (VEGFR2, PDGFRa, PDGFR $\beta$ and FGFR1). An additional slide was also used for hypoxia detection. After scanning the tissue sections, the antitumor and antivascular properties of RTKIs were correlated with their tumor tissue distribution data obtained by MALDI-MSI. 
Table 1. Chemical properties of the studied drugs

\begin{tabular}{|c|c|c|c|c|c|}
\hline & Motesanib & Pazopanib & Sorafenib & Sunitinib & Vatalanib \\
\hline Chemical formula & $\mathrm{C}_{22} \mathrm{H}_{23} \mathrm{~N}_{5} \mathrm{O}$ & $\mathrm{C}_{21} \mathrm{H}_{23} \mathrm{~N}_{7} \mathrm{O}_{2} \mathrm{~S}$ & $\mathrm{C}_{21} \mathrm{H}_{16} \mathrm{ClF}_{3} \mathrm{~N}_{4} \mathrm{O}_{3}$ & $\mathrm{C}_{22} \mathrm{H}_{27} \mathrm{FN}_{4} \mathrm{O}_{2}$ & $\mathrm{C}_{20} \mathrm{H}_{15} \mathrm{ClN}_{4}$ \\
\hline Molecular weight (g/mol) & 373.45 & 437.52 & 464.82 & 398.47 & 346.81 \\
\hline Monoisotopic mass $[\mathrm{M}+\mathrm{H}]^{+}(\mathrm{m} / \mathrm{z})$ & 374.199 & 438.170 & 465.093 & 399.218 & 347.105 \\
\hline Fragment ions $(m / z)$ & $212.1 ; 189.1 ; 163.1$ & $421.1 ; 357.1 ; 342.1$ & $447.1 ; 425.1 ; 270.2 ; 252.2$ & $326.1 ; 283.1$ & $\begin{array}{l}320.2 \\
311.2 \\
294.2 \\
268.1 \\
254.1 \\
220.2\end{array}$ \\
\hline
\end{tabular}

\section{Results}

\section{MALDI-MSI is an eligible tool to characterize antiangiogenic RTKIs in malignant tissue}

Monoisotopic mass and fragmentation pattern of each drug compound were defined on a MALDI target plate. When applied to the tissue surface, drug molecules showed similar ionization and fragmentation properties to those generated on the MALDI plate: the same monoisotopic masses and fragment ions detected on both surfaces are shown in Table 1.

The monoisotopic mass of motesanib was detected at $m / z$ 374.199. Fragmentation of the molecule resulted in ions at $\mathrm{m} / \mathrm{z}$ 212.1, which corresponds to the split at the amide bond of nicotinamide. The fragment ions corresponding to the indoline formamide moiety were identified at $\mathrm{m} / \mathrm{z}$ 189.1. Cleavage of the pyridine moiety and charge retention resulted fragment ions at $m / z$ 163.1.

Pazopanib was detected at $\mathrm{m} / \mathrm{z}$ 438.17. Subsequent MS/MS fragmentation of the precursor ions led to the loss of the amidogen group, generating fragment ions at $m / z$ 421.1. Further loss of the sulfur dioxide eventuated fragment ions at $m / z$ 357.1, while the presence of fragment ions at $\mathrm{m} / \mathrm{z} 342.1$ indicated the loss of an additional methyl group.

Sorafenib was found with a monoisotopic mass of $\mathrm{m} / \mathrm{z}$ 465.093. Dehydroxylation of the formamide moiety and subsequent bond retention resulted in fragment ions at $\mathrm{m} / \mathrm{z}$ 447.1, while cleavage of the pyridine ring eventuated fragment ions at $m / z 425.1$. Fragmentation of the molecule also led to detection of ions at $m / z 270.2$, corresponding to the loss of the chloro-trifluoromethyl-phenylamine group. Presence of fragment ions at $m / z 252.2$ indicated the cleavage of the chloro-trifluoromethyl-phenyl ring and the scission of the carboxamide group.

Sunitinib was identified at $m / z 399.218$ with fragment ions at $m / z 326.1$ and 283.1, in line with a recently published study from our group [36].
The monoisotopic mass of vatalanib was present at $m / z$ 347.105. Scission of the benzene ring resulted in the generation of ions at $m / z$ 320.2. Loss of the chloride eventuated fragment ions at $\mathrm{m} / \mathrm{z}$ 311.2, while decomposition of the phthalazin-amine ring led to the detection of ions at $\mathrm{m} / \mathrm{z} 294.2$. Loss of the pyridine moiety resulted in fragment ions at $m / z$ 268.1, while cleavage of the methylpiridyne group indicated the detection of ions at $\mathrm{m} / \mathrm{z}$ 254.1. Loss of the chlorophenil-amine group resulted in fragment ions at $m / z$ 220.2. Chemical properties of drug compounds are shown in Table 1.

\section{Antiangiogenic RTKI concentration and distribution show drug- and tumor type-specific variations in malignant tissue}

Calibration of the drug molecules resulted in linear correlation between concentration and normalized average signal intensity for all compounds in the examined concentration range (Figure S1). In both animal models, all the five drugs absorbed successfully with notable signal intensities being observed in the peripheral blood (data not shown). Because of the possibility of generating nonspecific precursor ion peaks from the tissue itself, the average signal intensities obtained from RTKI-treated tumors were compared with the average signal intensities of non-treated control tumors. Based on the calibration curves, average signal intensities were translated into drug concentration $(\mu \mathrm{mol} / \mathrm{mL})$ data. While intratumoral sorafenib and vatalanib levels did not differ between drug-treated and control C26 tumors, the concentrations of motesanib, sunitinib and pazopanib were significantly elevated (vs. control), with the highest values detected in the sunitinib-treated animals $(\mathrm{P}<0.05$ for all comparisons; Figure 2).

Importantly, the above described drug concentrations refer to the entire tumor section and striking differences in the drug distribution were observable within the in vivo-treated tumors. As for sunitinib, the drug was always homogeneously 
distributed within the viable C26 tumor areas and necrotic regions showed notably lower signal intensities (Figure 3 and Figure S3). In contrast, motesanib was seen only in one third of the C26 tumors at relatively high levels in connected areas and the intratumoral distributions of this RTKI and pazopanib (both of which were also present at relatively high average tumor tissue levels in C26 tumors; Figure 2) were inhomogeneous with the highest signal intensities observed in necrotic areas (Figure S3). Only traces of sorafenib and vatalanib were detected in the C26 model. Notably, motesanib, pazopanib and sorafenib were detected only at trace-level in C38 tumors. Representative images of intratumoral antiangiogenic RTKI distributions are shown in Figure 3.

In a previously published study, we found significantly decreased C38 tumor burdens in
C57Bl/6 mice treated with vatalanib [38]. Accordingly, in order to investigate why mice bearing C26 tumors respond notably poorer to vatalanib than those with C38 tumors, we also utilized MALDI-MSI of C38 tumors and addressed whether there are animal model-specific variations in the tumor tissue penetration and distribution of antiangiogenic RTKIs. In contrast to the C26 model, in C38 tumors, besides sunitinib, vatalanib was also well-distributed with notable signal intensities (Figure 3 ). In line with this, in vatalanib-treated mice bearing $\mathrm{C} 38$ tumors, the intratumoral drug concentration was significantly higher than that in the group of untreated controls $(\mathrm{P}=0.0006$, Figure 2$)$. It is also important to mention that we found significantly higher vatalanib concentrations in C38 than in C26 tumors (0.116 $\mu \mathrm{mol} / \mathrm{mL}$ vs $0.178 \mathrm{nmol} / \mathrm{mL}, \mathrm{P}=0.0025)$.

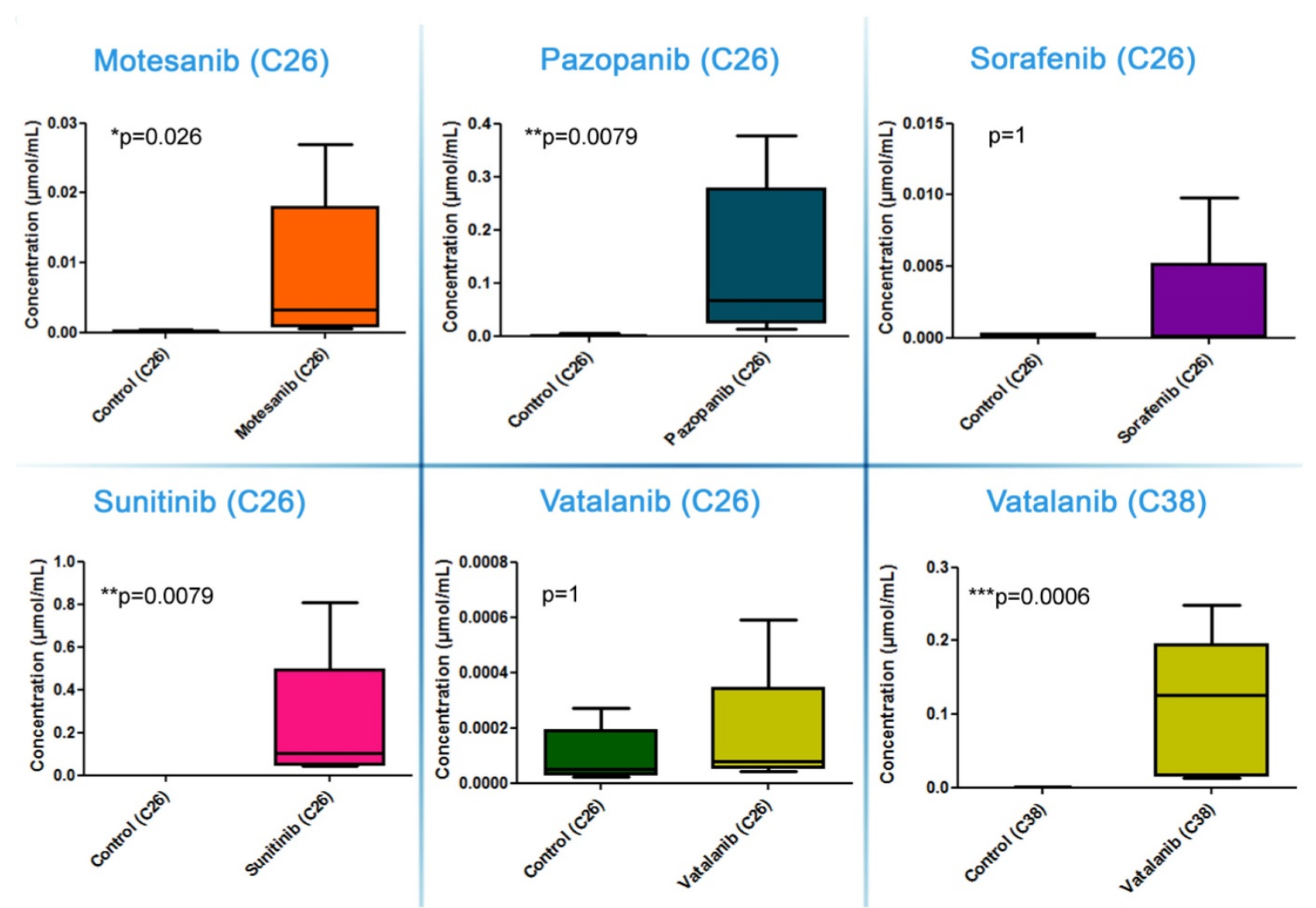

Figure 2. Tumor tissue concentrations of antiangiogenic RTKIs. Signal intensities (normalized to TIC) of the appropriate RTKIs in treated tumors and the same non-specific normalized $\mathrm{m} / \mathrm{z}$ values measured in control tumors were used to calculate intratumoral drug concentrations. Data are shown as box (first and third quartiles) and whisker (maximum to minimum) plots with the mean (horizontal bar) from 6 animals per group. 

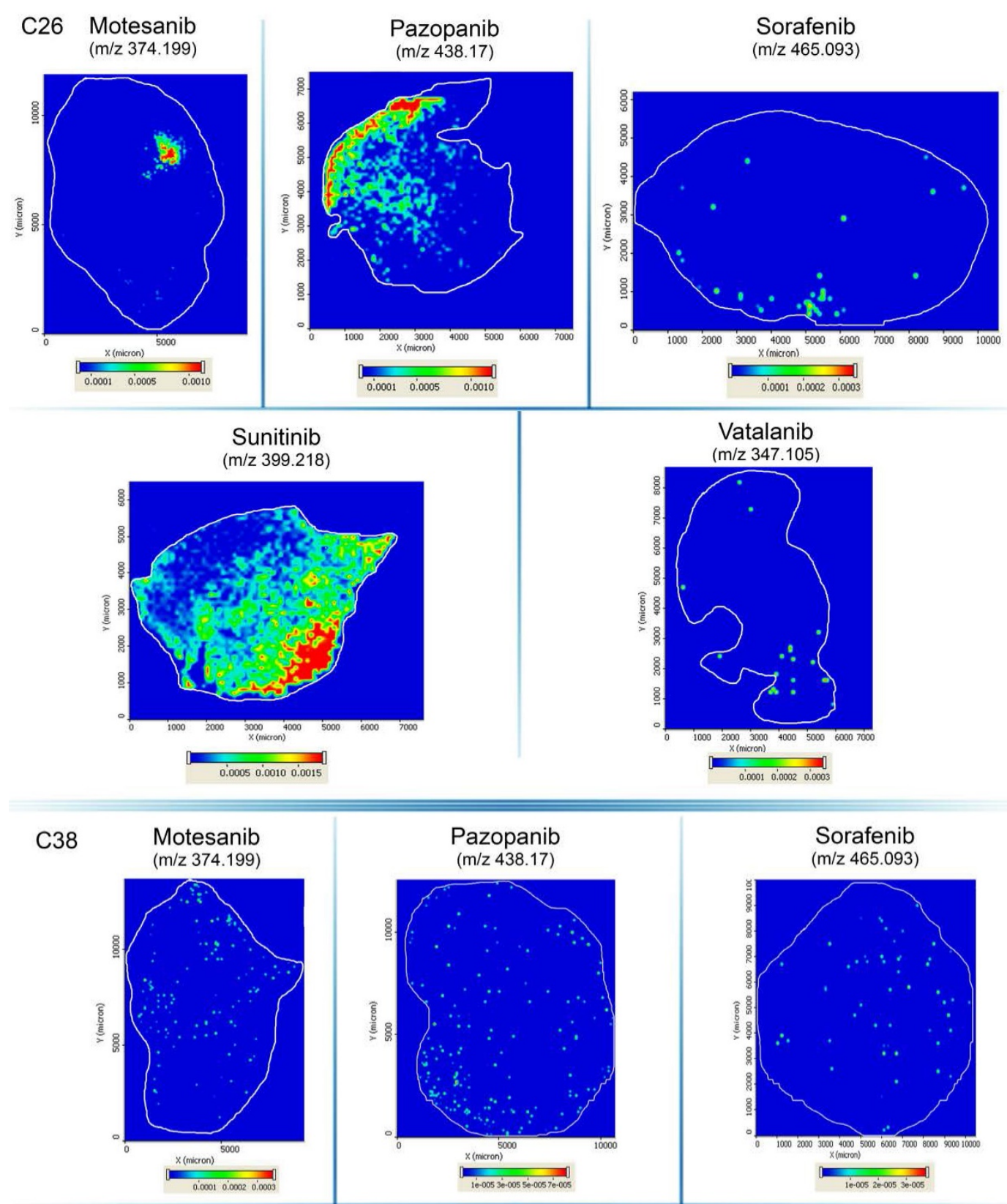

$\underset{(\mathrm{m} / \mathrm{z} 399.218)}{\text { Sunitinib }}$

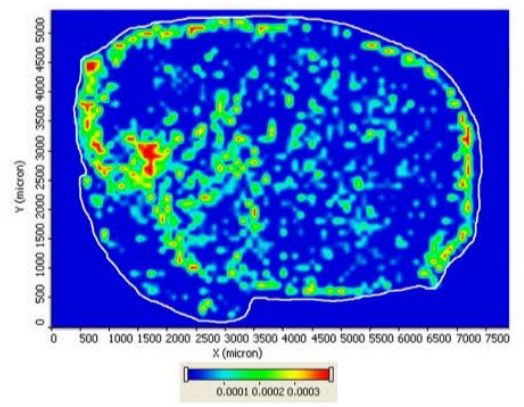

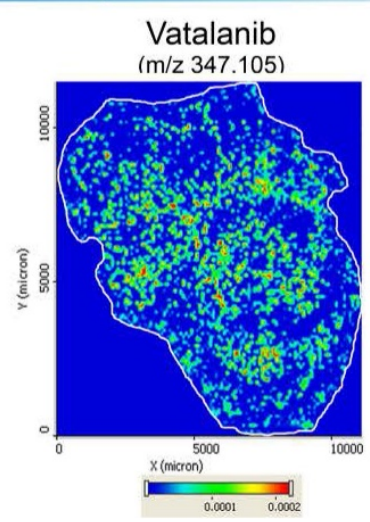

Figure 3. Representative images of drug distribution in C26 and C38 tumors after two weeks of treatment with different antiangiogenic RTKIs. Precursor ion signals of RTKIs were normalized to TIC. 

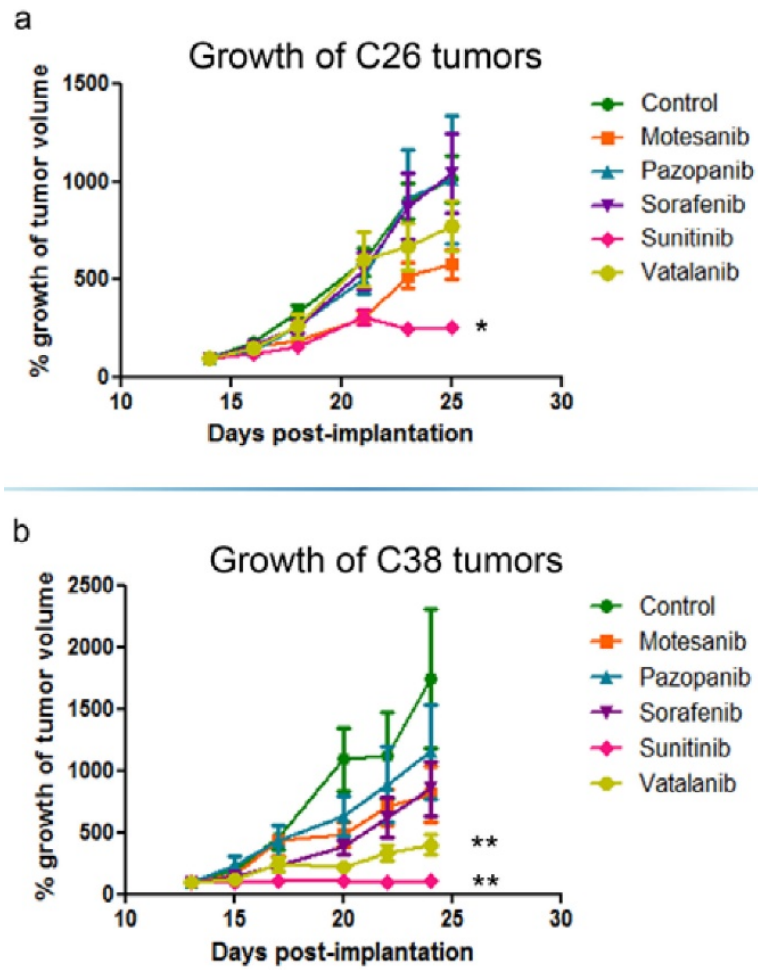

Figure 4. In vivo growth inhibition of $\mathrm{C} 26$ and $\mathrm{C} 38$ tumors. Balb/C (C26) and C57BI/6 (C38) mice were randomized to receive either vehicle $(n=6)$ or $100 \mathrm{mg} / \mathrm{kg}$ RTKI ( $n=6 /$ subgroup) treatment p.o. 5 times a week for two weeks. Out of the five different antiangiogenic RTKIs (motesanib, pazopanib, sorafenib, sunitinib and vatalanib), only sunitinib reduced significantly the in vivo growth of $\mathrm{C} 26$ mouse colon adenocarcinoma cells in Balb/C mice (a). In the C38 model, besides sunitinib, vatalanib also demonstrated a significant growth-inhibitory effect $(\boldsymbol{b})$. Growth curves are means for six mice per group; bars, SEM. Mean tumor volumes at the beginning of treatments were $155.3 \pm 25.4 \mathrm{~mm}^{3}$ and $376.9 \pm 51.2 \mathrm{~mm}^{3}$ in the $\mathrm{C} 26$ and $\mathrm{C} 38$ models, respectively. $* \mathrm{P}=0.0018, * * \mathrm{P}=0.0048$

\section{Intratumoral levels and distribution of antiangiogenic RTKIs critically determine their antitumor potential}

The growth of s.c. tumors in mice is known to be angiogenesis-dependent [41]. Thus, next we assessed the antivascular and antitumor activities of the five different antiangiogenic RTKIs (motesanib, pazopanib, sorafenib, sunitinib and vatalanib) in Balb/ $\mathrm{C}$ and $\mathrm{C} 57 \mathrm{Bl} / 6$ mice bearing s.c. syngeneic $\mathrm{C} 26$ and C38 tumors, respectively. Strikingly, and in line with the drug concentration and distribution data presented above, C26 tumor burden was reduced significantly only in sunitinib-treated animals $(P=0.0018)$ and no significant growth-inhibitory effect of motesanib, pazopanib, sorafenib or vatalanib was observed (Figure 4). In accordance with its significant antitumor potential, sunitinib showed the broadest spectrum of antivascular activity in the C26 model: it significantly increased intratumoral hypoxia $(\mathrm{P}=0.0152$; Figure 5) and suppressed microvessel areas $(\mathrm{P}<0.0001$; Figure 6) and VEGFR2 and pericyte desmin expressions $(\mathrm{P}=0.0353$ and $\mathrm{P}=0.0135$, respectively; Figures S4-5). As shown in Figure 6 and Figure S5, significantly decreased microvessel areas (in case of motesanib and sorafenib, $\mathrm{P}<0.05)$ and desmin expressions (in case of motesanib; $\mathrm{P}<0.05$ ) were also observed sporadically in the other treatment groups. Nevertheless, in contrast to the potent antitumor activity of sunitinib against C26 tumors, none of these random antivascular effects did translate into a significant tumor burden-suppressing potential in the C26 model (Figure 4).

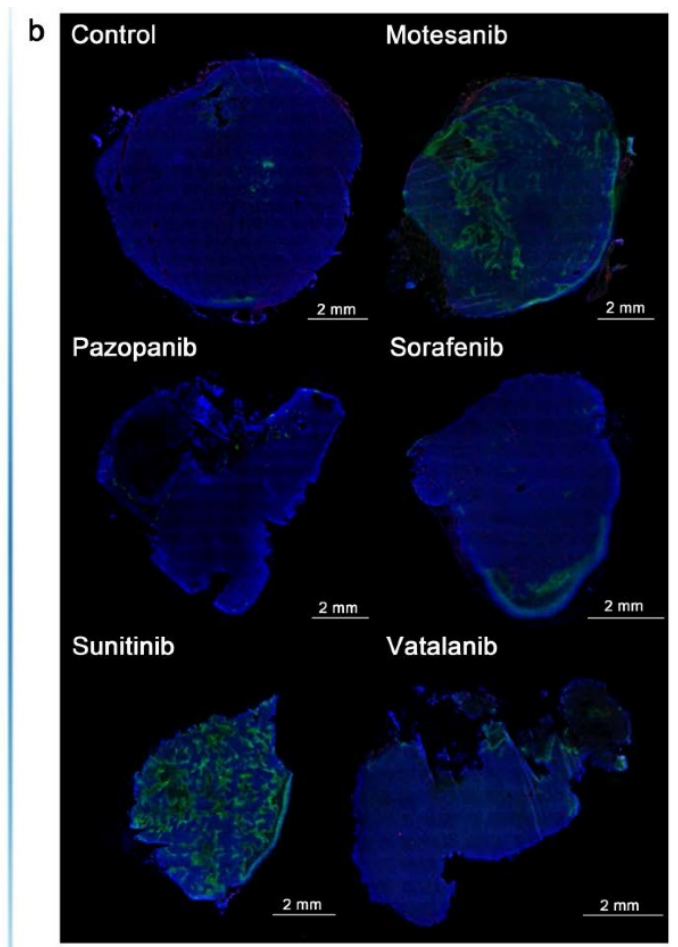

Figure 5. Graph (a) and representative images $(\boldsymbol{b})$ of hypoxic area ratios in the $\mathrm{C} 26$ model. Hypoxic area ratios are shown in the percentage of the total tumor section. Green, anti-pimonidazole staining for hypoxia; blue, nuclear staining with Hoechst. $* \mathrm{P}=0.0152$

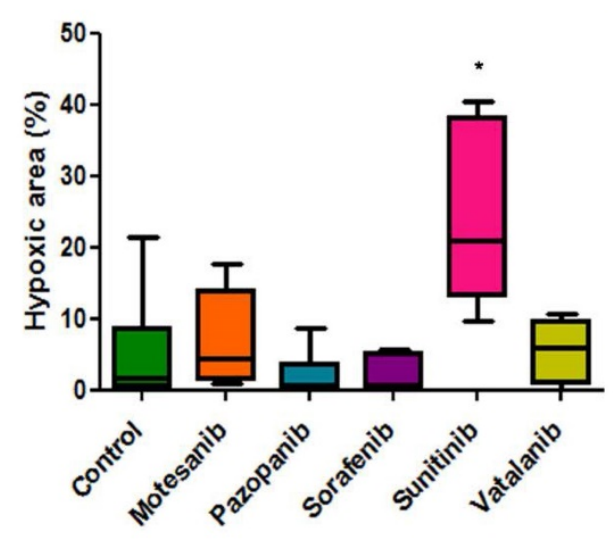

Pimonidazole Hoechst 
a

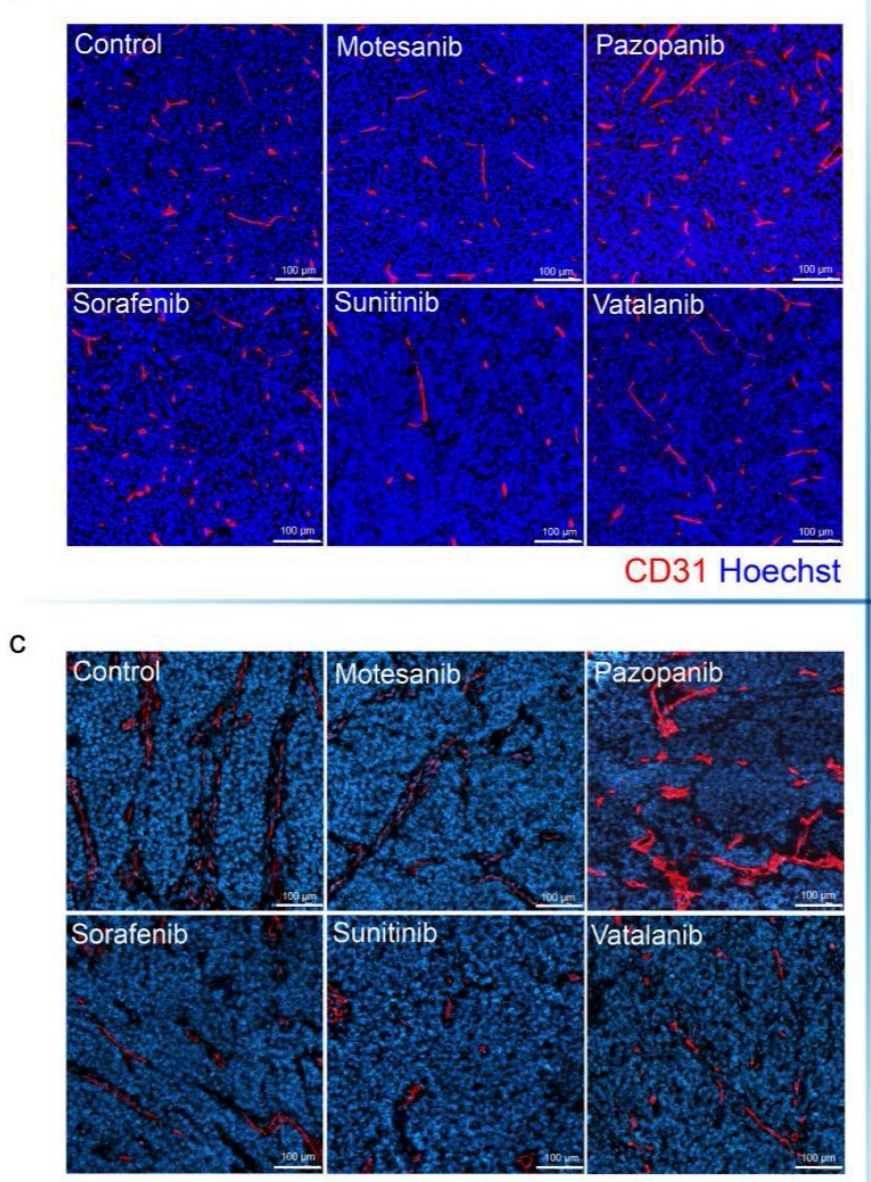

b

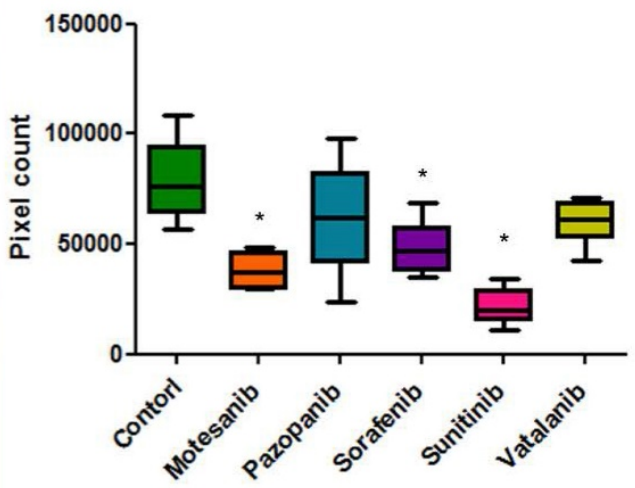

d

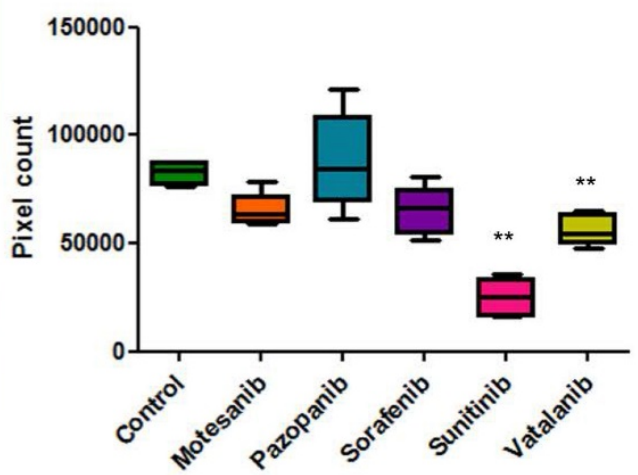

CD31 Hoechst

Figure 6. Microvessel areas of mouse C26 (a, b) and C38 (c, d) tumors. Antiangiogenic RTKI-treated C26 (a) and C38 (c) tumors were labeled with the endothelial cell marker CD31 (red) and with Hoechst33342 (as nuclear counterstain; blue). Microvessel areas of C26 (b) and C38 (d) tumors were calculated by counting the number of CD31-positive pixels in the total area of ten intratumoral regions. In (b and $\mathbf{d}$ ), data are shown as box (first and third quartiles) and whisker (maximum to minimum) plots with the mean (horizontal bar) from 6 animals per group. $* \mathrm{P}<0.05 ; * * \mathrm{P}<0.03$

C26 tumors were also immunohistochemically characterized for pericyte aSMA (Figure S6), laminin (an endothelial basement membrane component; Figure S7) and, besides VEGFR2 (Figure S4), for additional target receptors of the tested drugs (i.e. for PDGFRa, PDGFR $\beta$ and FGFR1; Figure S8-9). However, no statistically significant differences were detected in the tumor tissue expressions of these markers between control animals and mice in any of the RTKI treatment groups (data not shown).

Because vatalanib did not influence tumor growth or vascularization in the C26 model in the current study, next we sought to recapitulate the significant antitumor effects of vatalanib demonstrated earlier by our group in the C38 model [38]. As expected, we observed a robust and significant growth-inhibitory effect of vatalanib when administered to $\mathrm{C} 57 \mathrm{Bl} / 6$ mice bearing subcutaneously growing C38 tumors $(\mathrm{P}=0.0048$; Figure 4). In addition, a significant decrease of intratumoral microvessel areas was also observed for vatalanib in the $\mathrm{C} 38$ model $(\mathrm{P}<0.03$, Figure 6$)$. These results are of crucial importance because, as mentioned above, although vatalanib was not present with a relevant intratumoral distribution and thus did not show antiangiogenic or antitumor activity in the C26 model, this RTKI was well-distributed with notable signal intensities in C38 tumors (Figure 3). Importantly, besides vatalanib, sunitinib also exerted significant antitumor $(\mathrm{P}=0.0048$, Figure 4) and antivascular $(\mathrm{P}<0.03$, Figure 6$)$ activities in the C38 model. However, similarly to the C26 model - and in line with the above described poor intratumoral distributions of motesanib, pazopanib and sorafenib (Figure 3), no significant tumor growth inhibitory (Figure 4) or antiangiogenic (Figure 6) effects were observed when C38 tumor-bearing mice were treated with any of these latter three RTKIs.

\section{Discussion}

Although there are different concepts explaining resistance to angiogenesis inhibition $[9,10]$, the 
significance of insufficient tumor tissue drug penetration in primary resistance to antiangiogenic treatments has not yet been explored. Based on our current results, we propose that the intratumoral concentration and distribution and thus the antivascular and antitumor potential of antiangiogenic RTKIs are tumor model-specific and, moreover, that primary resistance to these drugs involves inadequate tumor tissue drug penetration.

Preclinical studies investigating the efficacy of combined antiangiogenic and cytotoxic chemotherapy treatments have provided promising results on intratumoral drug distributions of chemotherapeutic agents [42, 43]. However, clinical trials evaluating antiangiogenic drugs in patients with solid malignancies have been disappointingly modest [9, 10], and recent clinical data raised serious concern that bevacizumab (a humanized anti-VEGF antibody) can significantly reduce the uptake of chemotherapy by human tumors [44]. Of note, this is in contrast to the "vessel normalization theory" proposed by Jain and colleagues whereby treatment with an antiangiogenic agent such as bevacizumab [45] normalizes the chaotic tumor blood vessel network thus increasing chemotherapeutic drug delivery. It is also unclear whether antiangiogenic RTKIs - which are typically used as monotherapies in the indications for which they are so far approved (e.g. renal and liver cancers) - can efficiently penetrate tumor tissue and can reach all of the intratumoral areas. To the best of our knowledge, this is the first study reporting the head-to-head comparison of the intratumoral concentrations and distributions of various unlabeled antiangiogenic RTKIs by MSI. We found that oral administration of motesanib, pazopanib, sorafenib, sunitinib or vatalanib resulted in the absorption of all the five drugs with notable signal intensities being observed in the circulation. Surprisingly, only motesanib, pazopanib and sunitinib treatments resulted in significantly elevated intratumoral drug levels in the C26 model with the highest concentrations and the most homogeneous tumor tissue distributions observed in sunitinib-treated animals. The intratumoral distributions of motesanib and pazopanib were less homogeneous and notable signal intensities were confined to necrotic areas of C26 tumors. While reasons for these differences remain unclear, a possible explanation is that some antiangiogenic RTKIs given at standard doses may impair the efficacy of their own tumor tissue uptake and distribution. This phenomenon of reduced tumor blood capillary network functionality (i.e. "impaired capillary normalization") by some of the tested RTKIs could be the consequence of the applied standard drug doses and treatment schedules that had been approved for maximal antivascular effects with tolerable host toxicity but not for vessel normalization. In line with this assumption, improved chemotherapeutic drug delivery was reported at reduced but not at standard antiangiogenic drug doses [46]. Importantly, however, tumor samples analyzed at the beginning (day 1) of antiangiogenic RTKI treatments (data not shown) demonstrated similar drug distribution patterns to that observed in tumors treated for two weeks. Thus, the aforementioned assumption of impaired capillary normalization caused by long-term antiangiogenic RTKI treatment is not supported by our findings.

Furthermore, one could also assume that since PDGF-B is a key survival factor for the pericyte population and pericytes have a crucial role in the maintenance of vascular stability [47], RTKIs with potent anti-PDGFR $\beta$ activity may not promote normalization but, instead, might destabilize the vasculature and thus interfere with drug delivery. Our actual findings, however, do not support this assumption: treatment with sunitinib (the tested RTKI with the lowest IC50 value against PDGFR $\beta$, [18]) significantly decreased the pericyte coverage of tumor capillaries (as assessed by desmin expression). Notably, because all the five investigated RTKIs are highly bound to plasma proteins [48-51], it is also unlikely that their distinctive intratumoral distributions are due to their different plasma protein-binding profile.

In C26 tumors, the most homogeneous intratumoral drug patterns have been observed in sunitinib-treated animals but only traces of vatalanib were detected. In contrast, besides sunitinib, vatalanib was always detectable at homogeneously high concentrations throughout the malignant tissue in the C38 model. Chances, therefore, are that besides their dose, schedule and direct antivascular activity, the phenotype of the host vasculature and/or the tumor type are also likely to influence the tumor tissue levels and distribution of antiangiogenic RTKIs. The possible mechanisms linking inadequate antiangiogenic RTKI tumor concentration and endothelial- and tumor-specific characteristics involve lysosomal degradation of RTKIs [52] and increased RTKI efflux by the tumor [53] or the endothelial [54] cells or both.

There is a substantial volume of literature on the potential mechanisms that can lead to tumor resistance against antiangiogenic RTKIs [55]. These include hypoxia-driven mechanisms, the activation of compensatory angiogenic molecular pathways, the mobilization of myeloid or endothelial progenitor cell populations, the downregulation of target receptors in endothelial or tumor cells and also a switch to an 
alternative vascularization mechanism such as intussusceptive angiogenesis [38] or vessel-cooption [13]. Although suboptimal pharmacokinetics have been also described [56], so far most studies dealing with antiangiogenic RTKIs and drug resistance in solid tumors have focused on the above mechanisms. The key finding of the current study is that in comparison with tumor tissue drug concentrations, intratumoral distribution of antiangiogenic RTKIs critically determines their therapeutic efficacy. However, it is also important to mention here that besides their activity exerted on the tumor vessels, antiangiogenic RTKIs may also have direct antitumor effects via inhibition of one or more target receptors expressed by the tumor cells (Figures S4, S8-S9). As the tumor mass grows and the given antiangiogenic RTKI exerts its antivasular effects, blood capillaries may become nonfunctional or separated by longer distances resulting in limited drug delivery to RTK expressing tumor cells located distally from functional blood capillaries. Thus, the net result of antiangiogenic RTKI treatment in solid tumors might be tightly balanced by the (potentially opposing) antivascular and direct antitumor effects of these drugs.

Nevertheless, as mentioned above, in addition to sprouting angiogenesis (the main target of antiangiogenic drugs), it is today evident that tumors can acquire their vasculature also via alternative (non-sprouting) mechanisms [9], including vasculogenic mimicry [57], intussusceptive microvascular growth [38], postnatal vasculogenesis [58], glomeruloid angiogenesis [59] and vessel co-option [4]. Both from our group and from others there is a growing body of evidence that these non-sprouting vascularization mechanisms can interfere with the efficacy of the current antiangiogenic treatments [13, 60-63]. Therefore, our current studies using subcutaneous models (where sprouting angiogenesis dominates) need to be extended into studies utilizing both orthotopic primary tumors of different origin and metastatic animal models in order to fully explore the potential of the platform presented in the current manuscript.

In conclusion, the therapeutic efficacy of antiangiogenic RTKIs is critically determined by their intratumoral distribution. Our current findings demonstrate the potential of MALDI-MSI to help in optimizing the dose and schedule and thus the antivascular and antitumor effects of RTKIs. This potential of MALDI-MSI to study the localization of unlabelled small molecule antiangiogenic RTKIs in malignant tumors is of crucial importance because there is a pressing need for biomarkers of anti-angiogenic therapy in the clinics [64].

\section{Supplementary Material}

Supplementary figures and tables.

http://www.thno.org/v07p0400s1.pdf

\section{Acknowledgements}

The authors were supported by AIK 12-1-2013-0041 (BD, SP, JT), the Hungarian National Research, Development and Innovation Office (K109626, K108465 and SNN114490; BD) (K84173 and K116295; JT), the Semmelweis University Start-Up grant (40148-11658) and the Vienna Fund for Innovative Interdisciplinary Cancer Research (BD). ST was recipient of an EACR Travel Fellowship, the Hungarian Pulmonology Foundation Research Fellowship and the Ernst Mach-Stipendium. AV is grateful for the Innovative Support 2011-039226 for CREATE Health. This work was also supported by grants from the Mrs. Berta Kamprad Foundation, Ingabritt \& Arne Lundbergs forskningsstiftelse and the Crafoord Foundation.

\section{Authors' contributions}

BD, GMV, SP, VL, WK and THH conceived the study and/or contributed to the interpretation of the data. $\mathrm{BD}, \mathrm{BH}$ and $\mathrm{OK}$ wrote the manuscript. JT, AT, ST, IK, MAH and TM were responsible for performing the animal experiments and the immunohistochemical analysis of the tumors. MR, AV, KW, YS and OK performed the MALDI-MSI analyses. TK helped in the statistical analyses. All authors read and approved the manuscript.

\section{Competing Interests}

The authors have declared that no competing interest exists. The funders had no role in study design, data collection, analysis and decision to publish or preparation of the paper.

\section{References}

1. Hanahan D, Weinberg RA. Hallmarks of cancer: the next generation. Cell. 2011; 144: 646-74.

2. Bugyik E, Dezso K, Reiniger L, Laszlo V, Tovari J, Timar J, et al. Lack of angiogenesis in experimental brain metastases. J Neuropathol Exp Neurol. 2011; 70: 979-91.

3. Szabo V, Bugyik E, Dezso K, Ecker N, Nagy P, Timar J, et al. Mechanism of tumour vascularization in experimental lung metastases. J Pathol. 2015; 235: 384-96.

4. Dome B, Paku S, Somlai B, Timar J. Vascularization of cutaneous melanoma involves vessel co-option and has clinical significance. J Pathol. 2002; 197: 355-62.

5. Tebbutt N, Kotasek D, Burris HA, Schwartzberg LS, Hurwitz H, Stephenson I, et al. Motesanib with or without panitumumab plus FOLFIRI or FOLFOX for the treatment of metastatic colorectal cancer. Cancer chemotherapy and pharmacology. 2015; 75: 993-1004.

6. Giatromanolaki A, Koukourakis MI, Sivridis E, Gatter KC, Trarbach T, Folprecht G, et al. Vascular density analysis in colorectal cancer patients treated with vatalanib (PTK787/ZK222584) in the randomised CONFIRM trials. British journal of cancer. 2012; 107: 1044-50.

7. Wilson PM, Yang D, Azuma M, Shi MM, Danenberg KD, Lebwohl D, et al. Intratumoral expression profiling of genes involved in angiogenesis in colorectal cancer patients treated with chemotherapy plus the VEGFR inhibitor PTK787/ZK 222584 (vatalanib). The pharmacogenomics journal. 2013; 13: 410-6. 
8. Koukourakis MI, Giatromanolaki A, Sivridis E, Gatter KC, Trarbach T, Folprecht G, et al. Prognostic and predictive role of lactate dehydrogenase 5 expression in colorectal cancer patients treated with PTK787/ZK 222584 (vatalanib) antiangiogenic therapy. Clinical cancer research : an official journal of the American Association for Cancer Research. 2011; 17: 4892-900.

9. Dome B, Hendrix MJ, Paku S, Tovari J, Timar J. Alternative vascularization mechanisms in cancer: Pathology and therapeutic implications. Am J Pathol. 2007; 170: 1-15.

10. Vasudev NS, Reynolds AR. Anti-angiogenic therapy for cancer: current progress, unresolved questions and future directions. Angiogenesis. 2014; 17: 471-94.

11. Dvorak HF. Tumor Stroma, Tumor Blood Vessels, and Antiangiogenesis Therapy. Cancer J. 2015; 21: 237-43.

12. Ebos JM, Kerbel RS. Antiangiogenic therapy: impact on invasion, disease progression, and metastasis. Nat Rev Clin Oncol. 2011; 8: 210-21.

13. Kuczynski EA, Yin M, Bar-Zion A, Lee CR, Butz H, Man S, et al. Co-option of Liver Vessels and Not Sprouting Angiogenesis Drives Acquired Sorafenib Resistance in Hepatocellular Carcinoma. J Natl Cancer Inst. 2016; 108.

14. Sharma K, Suresh PS, Mullangi R, Srinivas NR. Quantitation of VEGFR2 (vascular endothelial growth factor receptor) inhibitors--review of assay methodologies and perspectives. Biomed Chromatogr. 2015· 29. 803-34.

15. Polverino A, Coxon A, Starnes C, Diaz Z, DeMelfi T, Wang L, et al. AMG 706, an oral, multikinase inhibitor that selectively targets vascular endothelial growth factor, platelet-derived growth factor, and kit receptors, potently inhibits angiogenesis and induces regression in tumor xenografts. Cancer research. 2006; 66: 8715-21.

16. Kumar R, Knick VB, Rudolph SK, Johnson JH, Crosby RM, Crouthamel MC, et al. Pharmacokinetic-pharmacodynamic correlation from mouse to human with pazopanib, a multikinase angiogenesis inhibitor with potent antitumor and antiangiogenic activity. Molecular cancer therapeutics. 2007; 6: 2012-21.

17. Wilhelm SM, Carter C, Tang L, Wilkie D, McNabola A, Rong H, et al. BAY 43-9006 exhibits broad spectrum oral antitumor activity and targets the RAF/MEK/ERK pathway and receptor tyrosine kinases involved in tumor progression and angiogenesis. Cancer research. 2004; 64: 7099-109.

18. Mendel DB, Laird AD, Xin X, Louie SG, Christensen JG, Li G, et al. In vivo antitumor activity of SU11248, a novel tyrosine kinase inhibitor targeting vascular endothelial growth factor and platelet-derived growth factor receptors: determination of a pharmacokinetic/pharmacodynamic relationship. Clinical cancer research : an official journal of the American Association for Cancer Research. 2003; 9: 327-37.

19. Wood JM, Bold G, Buchdunger E, Cozens R, Ferrari S, Frei J, et al. PTK787/ZK 222584, a novel and potent inhibitor of vascular endothelial growth factor receptor tyrosine kinases, impairs vascular endothelial growth factor-induced responses and tumor growth after oral administration. Cancer research. 2000; 60: 2178-89.

20. Kruser TJ, Wheeler DL, Armstrong EA, Iida M, Kozak KR, van der Kogel AJ, et al. Augmentation of radiation response by motesanib, a multikinase inhibitor that targets vascular endothelial growth factor receptors. Clinical cancer research : an official journal of the American Association for Cancer Research. 2010; 16: 3639-47.

21. Caenepeel S, Renshaw-Gegg L, Baher A, Bush TL, Baron W, Juan T, et al. Motesanib inhibits Kit mutations associated with gastrointestinal stromal tumors. Journal of experimental \& clinical cancer research : CR. 2010; 29 : 96.

22. Coxon A, Bush T, Saffran D, Kaufman S, Belmontes B, Rex K, et al. Broad antitumor activity in breast cancer xenografts by motesanib, a highly selective, oral inhibitor of vascular endothelial growth factor, platelet-derived growth factor, and Kit receptors. Clinical cancer research : an official journal of the American Association for Cancer Research. 2009; 15: 110-8.

23. Gril B, Palmieri D, Qian Y, Anwar T, Ileva L, Bernardo M, et al. The B-Raf status of tumor cells may be a significant determinant of both antitumor and anti-angiogenic effects of pazopanib in xenograft tumor models. PloS one. 2011; 6: e25625.

24. Gril B, Palmieri D, Qian Y, Smart D, Ileva L, Liewehr DJ, et al. Pazopanib reveals a role for tumor cell B-Raf in the prevention of HER2+ breast cancer brain metastasis. Clinical cancer research : an official journal of the American Association for Cancer Research. 2011; 17: 142-53.

25. Paesler J, Gehrke I, Gandhirajan RK, Filipovich A, Hertweck M, Erdfelder F, et al. The vascular endothelial growth factor receptor tyrosine kinase inhibitors vatalanib and pazopanib potently induce apoptosis in chronic lymphocytic leukemia cells in vitro and in vivo. Clinical cancer research : an official journal of the American Association for Cancer Research. 2010; 16: 3390-8.

26. Hashimoto K, Man S, Xu P, Cruz-Munoz W, Tang T, Kumar R, et al. Potent preclinical impact of metronomic low-dose oral topotecan combined with the antiangiogenic drug pazopanib for the treatment of ovarian cancer. Molecular cancer therapeutics. 2010; 9: 996-1006.

27. de Bouard S, Herlin P, Christensen JG, Lemoisson E, Gauduchon P, Raymond $\mathrm{E}$, et al. Antiangiogenic and anti-invasive effects of sunitinib on experimental human glioblastoma. Neuro-oncology. 2007; 9: 412-23.

28. Riesterer O, Oehler-Janne $\mathrm{C}$, Jochum W, Broggini-Tenzer A, Vuong V, Pruschy $\mathrm{M}$. Ionizing radiation and inhibition of angiogenesis in a spontaneous mammary carcinoma and in a syngenic heterotopic allograft tumor model: a comparative study. Radiation oncology. 2011; 6: 66.

29. Ullrich RT, Jikeli JF, Diedenhofen M, Bohm-Sturm P, Unruh M, Vollmar S, et al. In-vivo visualization of tumor microvessel density and response to anti-angiogenic treatment by high resolution MRI in mice. PloS one. 2011; 6: e19592.

30. Banerjee S, A'Hern R, Detre S, Littlewood-Evans AJ, Evans DB, Dowsett M, et al. Biological evidence for dual antiangiogenic-antiaromatase activity of the VEGFR inhibitor PTK787/ZK222584 in vivo. Clinical cancer research : an official journal of the American Association for Cancer Research. 2010; 16: 4178-87.

31. Jaeger-Lansky A, Cejka D, Ying L, Preusser M, Hoeflmayer D, Fuereder T, et al. Effects of vatalanib on tumor growth can be potentiated by mTOR blockade in vivo. Cancer biology \& therapy. 2010; 9: 919-27.

32. Locatelli SL, Giacomini A, Guidetti A, Cleris L, Mortarini R, Anichini A, et al. Perifosine and sorafenib combination induces mitochondrial cell death and antitumor effects in NOD/SCID mice with Hodgkin lymphoma cell line xenografts. Leukemia. 2013; 27: 1677-87.

33. Hu S, Niu H, Inaba H, Orwick S, Rose C, Panetta JC, et al. Activity of the multikinase inhibitor sorafenib in combination with cytarabine in acute myeloid leukemia. J Natl Cancer Inst. 2011; 103: 893-905.

34. Carlo-Stella C, Locatelli SL, Giacomini A, Cleris L, Saba E, Righi M, et al. Sorafenib inhibits lymphoma xenografts by targeting MAPK/ERK and AKT pathways in tumor and vascular cells. PloS one. 2013; 8: e61603.

35. Lim AY, Segarra I, Chakravarthi S, Akram S, Judson JP. Histopathology and biochemistry analysis of the interaction between sunitinib and paracetamol in mice. BMC pharmacology. 2010; 10: 14.

36. Torok S, Vegvari A, Rezeli M, Fehniger TE, Tovari J, Paku S, et al. Localization of sunitinib, its metabolites and its target receptors in tumour-bearing mice: a MALDI-MS imaging study. British journal of pharmacology. 2015; 172: 1148-63.

37. Dezso K, Bugyik E, Papp V, Laszlo V, Dome B, Tovari J, et al. Development of arterial blood supply in experimental liver metastases. Am J Pathol. 2009; 175: 835-43.

38. Paku S, Dezso K, Bugyik E, Tovari J, Timar J, Nagy P, et al. A new mechanism for pillar formation during tumor-induced intussusceptive angiogenesis: inverse sprouting. Am J Pathol. 2011; 179: 1573-85.

39. Rozsas A, Berta J, Rojko L, Horvath LZ, Keszthelyi M, Kenessey I, et al. Erythropoietin receptor expression is a potential prognostic factor in human lung adenocarcinoma. PloS one. 2013; 8: e77459.

40. Kilkenny C, Altman DG. Improving bioscience research reporting: ARRIVE-ing at a solution. Laboratory animals. 2010; 44: 377-8

41. Folkman J. What is the evidence that tumors are angiogenesis dependent? J Natl Cancer Inst. 1990; 82: 4-6.

42. Goldwirt L, Beccaria K, Carpentier A, Idbaih A, Schmitt C, Levasseur C, et al. Preclinical impact of bevacizumab on brain and tumor distribution of irinotecan and temozolomide. J Neurooncol. 2015; 122: 273-81.

43. Cesca M, Morosi L, Berndt A, Fuso Nerini I, Frapolli R, Richter P, et al. Bevacizumab-Induced Inhibition of Angiogenesis Promotes a More Homogeneous Intratumoral Distribution of Paclitaxel, Improving the Antitumor Response. Molecular cancer therapeutics. 2016; 15: 125-35.

44. Van der Veldt AA, Lubberink M, Bahce I, Walraven M, de Boer MP, Greuter $\mathrm{HN}$, et al. Rapid decrease in delivery of chemotherapy to tumors after anti-VEGF therapy: implications for scheduling of anti-angiogenic drugs. Cancer Cell. 2012; 21: 82-91.

45. Goel S, Wong AH, Jain RK. Vascular normalization as a therapeutic strategy for malignant and nonmalignant disease. Cold Spring Harb Perspect Med. 2012; 2: a006486

46. Kabbinavar F, Hurwitz HI, Fehrenbacher L, Meropol NJ, Novotny WF, Lieberman G, et al. Phase II, randomized trial comparing bevacizumab plus fluorouracil (FU)/leucovorin (LV) with $\mathrm{FU} / \mathrm{LV}$ alone in patients with metastatic colorectal cancer. J Clin Oncol. 2003; 21: 60-5.

47. Bergers G, Song S. The role of pericytes in blood-vessel formation and maintenance. Neuro-oncology. 2005; 7: 452-64.

48. Wang X, Owzar K, Gupta P, Larson RA, Mulkey F, Miller AA, et al. Vatalanib population pharmacokinetics in patients with myelodysplastic syndrome: CALGB 10105 (Alliance). Br J Clin Pharmacol. 2014; 78: 1005-13.

49. Deng Y, Sychterz C, Suttle AB, Dar MM, Bershas D, Negash K, et al. Bioavailability, metabolism and disposition of oral pazopanib in patients with advanced cancer. Xenobiotica. 2013; 43: 443-53.

50. Villarroel MC, Pratz KW, Xu L, Wright JJ, Smith BD, Rudek MA. Plasma protein binding of sorafenib, a multi kinase inhibitor: in vitro and in cancer patients. Invest New Drugs. 2012; 30: 2096-102.

51. Duckett DR, Cameron MD. Metabolism considerations for kinase inhibitors in cancer treatment. Expert Opin Drug Metab Toxicol. 2010; 6: 1175-93.

52. Gotink KJ, Broxterman HJ, Labots M, de Haas RR, Dekker H, Honeywell RJ, et al. Lysosomal sequestration of sunitinib: a novel mechanism of drug resistance. Clinical cancer research : an official journal of the American Association for Cancer Research. 2011; 17: 7337-46.

53. Gottesman MM, Pastan IH. The Role of Multidrug Resistance Efflux Pumps in Cancer: Revisiting a JNCI Publication Exploring Expression of the MDR1 (P-glycoprotein) Gene. J Natl Cancer Inst. 2015; 107.

54. Huang L, Perrault C, Coelho-Martins J, Hu C, Dulong C, Varna M, et al. Induction of acquired drug resistance in endothelial cells and its involvement in anticancer therapy. J Hematol Oncol. 2013; 6: 49

55. Broxterman HJ, Gotink KJ, Verheul HM. Understanding the causes of multidrug resistance in cancer: a comparison of doxorubicin and sunitinib. Drug Resist Updat. 2009; 12: 114-26. 
56. Arrondeau J, Mir O, Boudou-Rouquette P, Coriat R, Ropert S, Dumas G, et al. Sorafenib exposure decreases over time in patients with hepatocellular carcinoma. Invest New Drugs. 2012; 30: 2046-9.

57. Maniotis AJ, Folberg R, Hess A, Seftor EA, Gardner LM, Pe'er J, et al. Vascular channel formation by human melanoma cells in vivo and in vitro: vasculogenic mimicry. The American journal of pathology. 1999; 155: 739-52.

58. Dome B, Timar J, Ladanyi A, Paku S, Renyi-Vamos F, Klepetko W, et al Circulating endothelial cells, bone marrow-derived endothelial progenitor cells and proangiogenic hematopoietic cells in cancer: From biology to therapy. Critical reviews in oncology/hematology. 2009; 69: 108-24.

59. Dome B, Timar J, Paku S. A novel concept of glomeruloid body formation in experimental cerebral metastases. J Neuropathol Exp Neurol. 2003; 62: 655-61.

60. Bridgeman VL VP, Foo S, Bilecz A, Daley F, Kostaras E, Nathan MR, Wan E, Frentzas S, Schweiger T, Hegedus B, Hoetzenecker K, Renyi-Vamos F, Kuczynski EA, Vasudev NS, Larkin J, Gore M, Dvorak HF, Paku S, Kerbel RS, Dome B, Reynolds AR. Vessel co-option is common in human lung metastases and mediates resistance to anti-angiogenic therapy in preclinical lung metastasis models. J Pathol. 2016; in press.

61. Frentzas S, Simoneau E, Bridgeman VL, Vermeulen PB, Foo S, Kostaras E, et al. Vessel co-option mediates resistance to anti-angiogenic therapy in liver metastases. Nat Med. 2016.

62. Rubenstein JL, Kim J, Ozawa T, Zhang M, Westphal M, Deen DF, et al. Anti-VEGF antibody treatment of glioblastoma prolongs survival but results in increased vascular cooption. Neoplasia. 2000; 2: 306-14.

63. Leenders WP, Kusters B, Verrijp K, Maass C, Wesseling P, Heerschap A, et al. Antiangiogenic therapy of cerebral melanoma metastases results in sustained tumor progression via vessel co-option. Clin Cancer Res. 2004; 10: 6222-30.

64. Wehland M, Bauer J, Magnusson NE, Infanger M, Grimm D. Biomarkers for anti-angiogenic therapy in cancer. International journal of molecular sciences. 2013; 14: 9338-64. 